\title{
THROUGH THE LENS OF A WOMAN WITH SCHIZOAFFECTIVE DISORDER: A CASE STUDY
}

\author{
Simona Trifu ${ }^{*}$ 四 (iD), Emilia Șerban 2, Meryem Serdaroglu 2, Naomi Evelina Soare ${ }^{2}$ \\ *1 University of Medicine and Pharmacy "Carol Davila”, Bucharest, Romania \\ ${ }^{2}$ Faculty of Psychology and Educational Science, University of Bucharest, Romania
}

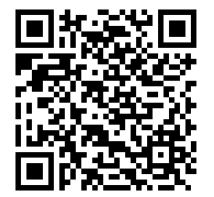

DOI: https://doi.org/10.29121/granthaalayah.v9.i3.2021.3805

Article Type: Research Article

Article Citation: Simona Trifu, Emilia Șerban, Meryem Serdaroglu, and Naomi Evelina Soare. (2021). THROUGH THE LENS OF A WOMAN WITH SCHIZOAFFECTIVE DISORDER: A CASE STUDY. International Journal of Research GRANTHAALAYAH, 9(3), 262-268. https://doi.org/10.29121/granthaa layah.v9.i3.2021.3805

Received Date: 16 March 2021

Accepted Date: 31 March 2021

Keywords:

Schizoaffective Disorder

Borderline Personality Disorder

Othello Syndrome

Capgras Syndrome

Psychodynamic Approach

\section{ABSTRACT}

Motivation/Background: Historically speaking, the distinction between manic-depressive disorders and schizophrenia finds itself in an unclear and vast spectrum bordered by the two illnesses. In this paper, we will present a case study that raises a question of diagnosis: bipolar disorder or schizoaffective disorder? Following the description of the symptoms and diagnosis criteria of each of the disorders, along with the personal data of the patient (the ones that are available to us), we will attempt analyzing the case as thoroughly as possible. The paper introduces the case of a 40-year-old woman who presents affective/mood related symptoms.

Method: psychiatric evaluation, psychiatric interview, psychodynamic interview and psychodynamic interpretation.

Results: The subject has a pathology of attachment developed over a structure with homosexual attachment choices. The multiple psychotraumas of childhood and the busy life history overlap with a vulnerability for emotional manifestations. She develops as axis I pathology a bipolar affective disorder, which at the moment takes the form of a mixed dispositional episode with psychotic phenomena. The artistic side makes it work markedly on delirious interpretativity, as it is to be appreciated the patient's effort not to completely detach from reality.

Conclusions: Late detection of these habits by the relatives, as well as other signs of psychiatric conditions, has contributed to an alteration of the identity of the patient and an inability to develop proper social behavior. After an overview of the patient's life experience, we can presume that the psychiatric condition is present and that it is evolving. The aim of the paper is to provide a theoretical viewpoint on this specific pathology, with particular features for this case study.

\section{INTRODUCTION}

\subsection{PATIENT DATA}

The patient, a 40-year-old female at the moment the interview was taken, is currently single and has never been married. The audio recording contains very little details about the patient's family, other than the brief mentioning of her sister, with whom she has a good relationship.

(C) 2021 The Author(s). This is an open access article distributed under the terms of the Creative Commons Attribution License, which permits unrestricted use, distribution, and reproduction in any medium, provided the original author and source are credited. 
The patient is currently in a homosexual relationship with M., which she mentions in the interview. They have been together for the past 7 months. It is not her first same-sex relationship as she mentions an ex-partner, C., after whom she claims she mourned for 7 years. The patient is planning to leave as quickly as possible for Paris together with her sister.

(The following information has been gathered after the interview)

The patient comes from a wealthy family. Her mother is a businesswoman with a very high social status and her father lives in Paris. Her mother has suffered greatly due to her daughter being unable to integrate socially. She has also tried to help the patient by finding her a job. However, the patient was unable to maintain employment for longer than 8 months, most likely due to her inability to cope with stress and rigidity of a workplace.

The patient has 4 citizenships, but no stable domicile or job. She has lived for a significant period of time in an artistic community of lesbians in Paris. Most of the women were provided for by their partners or their parents and their homosexual relationships were mostly a biproduct of boredom or extravagance, as opposed to the patient, who identifies herself a lesbian.

\subsection{MEDICAL HISTORY}

It appears the subject has been attending a psychologist for several years now. Previous to her internment, the patient had been on antidepressants.

Main diagnosis: Bipolar I disorder

The DSM V criteria for Bipolar disorder are the following: Abnormal disposition and persistent irritability, increased activity directed towards a goal as well as abnormal and/or sustained elevated energy levels lasting more than a week.

To establish the diagnosis of bipolar affective disorder (type 1), it is necessary to meet the following criteria for the manic episode. The manic episode may be preceded or followed by major hypomanic or depressive episodes. According to DSM V, the manic episode is represented by a specific duration of anomalously and persistently high, expansive, or irritable mood and abnormally and persistently goal-oriented action or energy, lasting for at least 1 week and occurring a whole day, every other day (or any duration if hospitalization is necessary).

In the patient's case, the number of symptoms presented are not enough to warrant a bipolar disorder (type 1) diagnosis. The patient only displays "racing thoughts" and "increase in goal-directed activity".

\subsection{PSYCHOLOGICAL EXAMINATION OF THE PATIENT'S CURRENT STATE}

General aspect: unkept, eccentrical, bizarre

Time and space awareness: no significant changes

Perception: quantitatively - hyperesthesia (cenesthopathy), qualitatively - visual illusions (Capgras syndrome) Attention: voluntary hypoprosexia, following deliriously centered hyperprosexia

Memory: no changes

Thought processing: verbal communication disorders related to the process of thinking: form - hyperactivity (bavardage), content - jargon aphasia at word level, circumstantiality, tangentiality, verbigeration at phrasal level. Formal disorders: racing thoughts.

Content disorders: jealousy delusion, obsessive thoughts and actions, homicidal ideation

Affectivity: hyperthymia, dysphoria, anxiety, irritability

Behavior: akathisia, hyperkinesia

Volition: hyperboulia

Social: decreasing

Life instincts: food intake - decreasing.

Circadian rhythm: insomnia when attempting to sleep.

Insight: present 
Through the Lens of A Woman With Schizoaffective Disorder: A Case Study

\section{MATERIALS AND METHODS}

In this article, we included details from psychiatric evaluation, psychiatric interview, psychodynamic interviews, and psychodynamic interpretations. The patient has benefited from psychiatric and psychological monitoring of the daily progression under treatment.

\section{RESULTS AND DISCUSSIONS}

\subsection{CONTENT OF THE PATIENT'S DISCOURSE}

The patient begins by talking about her ex-partner, M. Afterwards, she suddenly starts crying. She speaks in an overly aggressive and serious tone and switches very quickly from a sad mood to an upset, angry one ("I'm lost", "I'm angry, I have never been so angry before, it's the first time", "I just want to beat myself up"). The patient shows homicidal ideation: "I wouldn't have killed myself, but I would've killed her, killed M.".

The patient's speech is incoherent, at a phrasal level presenting circumstantiality, tangentiality and also taking a long time to finish some phrases and ideas: "I'm upset that.... no.... I thought that... I.... was completely open". The patient often has ruminations about the past and uncertainties, has metacognitions, fearing of what she could think or do ("I don't know what's real and what's not real from what she told me and this makes me feel crazy... or that I haven't seen"). The patient feels used ("She lied to me and used me and this makes me want to scream"), which causes her extreme anger. Her locus of control is external ("No one can control me"). She sometimes repeats the same sentences continuously (verbigeration): “I can't eat, I can't eat!”, “I don't know, I don't know, I don't know...”. The patient often switches between English and Romanian (possible jargon aphasia) which can suggest depersonalization, lack of a socio-cultural identity and issues with integrating into the community: "I have one single speed, I have to fight back, I am like a child". Emotional responses also change very quickly (crying, anger). Her speech is theatrical and presents obsessional tendencies: she declares that she mourned for 7 years after her last partner's death ("I mourned Carmen for 7 years"). Regarding her current relationship with M., she often resorts to stalking her throughout Bucharest, saying that she often has gone to places that she knows M. goes to frequently.

The patient begins talking about M.'s ex-partner, J., who died at the age of 32 because of a heart attack and affirms that "I thought I could save M. from sadness and mourning". She reveals she has hired the services of shamans (shows belief in magic, delusion), unable to distinguish between what's real and what's imaginary), one of the reasons for doing so being to establish communication with J. to ask her for her blessing for her relationship with M. The symptoms of dysphoria, irritability, psychomotor agitation, anger, hyperthymia are part of a psychotic phenomenon, namely the delusional idea where the patient identifies herself with J.: "I have created myself a myth, I don't know who J. is! I don't know who J. is", "Maybe J. is all I want to be". The patient has never met J., she only knows of her from stories, however she has always admired her: "She was a very brave person". "When I got into contact with M., I focused on this" (referring to the contact she actually wanted with J., via M.). The patient has a high level of sensibility, which is likely why she chose M. in a symbolic manner, to associate with J.'s genius, J. being a great painter of her generation. Furthermore, she says that M. picked fragile, but intense women, statement from which we observe an emotional ambivalence: "I am fragile, but also strong" and the patient even begins to doubt M.'s psychological state: "She is a narcissist, she is perverse", "If I knew she was pathological, I would not have gotten together with her".

Next, the patient talks about an episode where she was stopped at a traffic light and she believed she saw M. with a man, which was most likely an imagination, but after which she became convinced that $\mathrm{M}$. was cheating on her with a man. From this story we observe her delusional jealousy (Othello syndrome) and Capgras syndrome. She presents delusional interpretations and psychotic phenomena: after the event mentioned before, she had seen a man at a bakery and she was immediately convinced that he was the man M. betrayed her with and she wanted to harm him ("If I wasn't there with my sister, I don't know what I would've done").

On a physiological level, the patient specifies she suffers from insomnia and loss of appetite. She also has a hard time accepting the necessity of medication ("I don't want to be sedated, I don't want to!"), not necessarily because the patient wouldn't understand her disorder, but rather due to her need to have control without outside help ("I would like to be able to defend myself without medication"). 
The most relevant aspects from the patient's discourse are the following: severe depressive episodes, sleep and eating disorders, severe anger issues, feelings of guilt, homicidal ideation, delusional jealousy, illusions and obsessive tendencies.

\subsection{PERSPECTIVES FOR DIAGNOSIS}

The debut of schizophrenia is fairly often caused by psychological trauma, a trigger. The diagnosis is done through early examination of the patient, structuring the clinical picture of the schizophrenia and its persistence over more than six months along with the degenerative elements. Data can also be acquired through heteroanamnesis, from which important aspects such as a history of mental illness in the family, schizophrenogenic life conditions, premorbid personality with schizophrenic traits or even anamnestic elements that could suggest schizophrenia before any trauma has occurred.

The general age of onset for schizoaffective disorder is early adulthood, however it can appear at any time, from adolescence all the way to the later stages of life.

It is important to consider the fact that a large number of people are initially diagnosed with a psychotic disorder. Only afterwards, when the patterns of affective episodes become evident, will they receive a diagnosis of schizoaffective disorder.

In this study we have concluded the patient suffers of schizoaffective disorder, which means the patient presents the following:

- Symptoms of schizophrenia

- Affective/mood related symptoms

The patient has displayed in the aforementioned interview a symptom from the affective disorder spectrum (bipolar subtype), namely a mixed affective episode. Afterwards, during the recording, the patient has also displayed several clear elements related to schizophrenia. However, not only schizoaffective disorder has symptoms similar to bipolar affective disorder and schizophrenia but also:

1) schizophrenia that is associated with a manic/depressive episode, without meeting the criteria for schizoaffective disorder.

2) a manic episode with psychotic elements.

3) a major depressive episode with psychotic elements.

At least two symptoms of the disorder are present, namely:

1) Positive symptoms such as:

- delusions

- racing thoughts

- incoherent speech

- chaotic motor behavior

- illusions

2) Negative symptoms, such as:

- hypoprosexia (inability to concentrate, lack of stability and selective attention)

- avolition

- reduced spontaneous movement, in spite of the very aggressive behavior and communication.

Associated elements supporting this diagnosis are:

- Impaired Professional Life - the patient had worked for 8 months, but due to her condition she was unable to cope further;

- Impaired Social Life - the patient has a limited social circle with which she interacts and has difficulties taking care of herself on her own. These symptoms point to a socio-affective disorder, but the negative symptoms are less severe and more persistent compared to those of schizophrenia.

- several instances where the patient has shown sign of a major depressive disorder.

- During the analysis of this case, we have concluded that the patient presents borderline personality disorder traits as follows: 
- affective instability as a reaction to outside stimuli - unlike bipolar disorder, where the person switches from very positive to very negative emotions, in the case of borderline personality disorder the switch is between different negative emotions. Affective instability in the case of borderline personality disorder is also unique due to the fact that it manifests as a response to outside stimuli such as interpersonal conflicts and perceived rejection, which is what the patient is experiencing.

- Identity Issues - the patient has an unstable concept of self, so much so, we could call it very weakly defined. There is a possibility the lack of an integrated image of the self leads feelings of vast inner emptiness which manifest as physical sensations in the patient's chest or abdomen, a distinctive characteristic of this disorder.

- Relationship Issues - the patient frequently oscillates between idolizing and hating their romantic partners, the newly formed relationships often reaching a high level of intimacy and intensity very quickly and they are often followed by feelings that the other person is not as involved, available or attached (in the case of the patient, this is clearly observed in her relationship with M.)

- Anger Issues - intense and inadequate anger is a very normal emotion for the patient. She has great difficulty controlling her anger or expressing it in a productive manner. She worries the significant people in her life could leave, could neglect or reject her. It is a type of anxiety, that often comes as an answer to physical separation from her loved ones.

It is to be mentioned that the patient does not present any known medical condition (or at least none have been mentioned during the interview).

\section{Associated elements that support the diagnosis}

Family ties are strong, parents financially support the patient, the mother has made efforts to integrate her socially through finding her a job; the patient's sister often accompanies her outside, including when the patient wanted to visit a shaman.

\subsection{PSYCHODYNAMIC PERSPECTIVE}

\section{Ego and superego traits}

This model was first shown by Freud in 1923: The ego is the barrier between conscious and unconscious, representing the function of adaptation to reality. The Superego however is not a hereditary instance but is rather formed as the person gathers information about keeping certain tendencies in check. Kernberg (1993) notes about people diagnosed with borderline personality disorder that their capacity to express, care for themselves and to tolerate certain feelings of guilt when they behave aggressively, is just the first stage of internalization of the Superego's functions, as well as a possible emotional involvement in other people, which represents a reason for a favorable prognostic.

Concerning the patient, however, there is no such care about herself, and the anger and irritability reflect the persistence of primitive, defensive operations and a tendency to project in a purely defensive way, all the pressure and impulses of an impaired or even nonexistent Superego. The patient functions chaotically, often in a contradictory way, even immature ("I am a child that hasn't learned how to defend herself").

The patient wrestles continuously with emotional agitation, in addition to her strong and intense romantic attachments, from where comes the superimposing of anger issues with crying spells during the interviews.

Even though there are little details about the patient's family, we can deduce that no realistic parental images have been internalized during the Oedipian development because the ideal traits of the Superego are not available to the patient and therefore, she cannot access them - Freud himself says that the Superego is actually a result of the Oedipian complex. The patient therefore does not seem to even attempt tempering her forbidden impulses, rather she depends on the people around her ("If I wasn't with my sister, I don't know what I would've done") and seems to disregard socio-cultural limits that could symbolically represent parental authority even more so because they have never existed: the patient's father lives in France, her mother and sister in Romania and even herself has 4 citizenships and is always moving between one place and another.

From here on we have the issue of identity: in the patient's case the only stable part of it appears to be the psychosexual one. It appears the patient has no clear grasp of her personal or social identity, her speech often 
containing ambivalence or depersonalization, which can signal her Ego is not functioning correctly. Her Ego is fragile, emotionally unstable, ambivalent and sensitive to rejection. However, thanks to the support of her sister, possibly her therapist and other close friends and people, it is probable that the patient is able to use these traits of the Ego as defensive agents, a barrier between adaptive and maladaptive, in this case, a very thin, often unclear one.

\section{CONCLUSIONS AND RECOMMENDATIONS}

Mental conditions that are unresolved have more than mere psychological and functional effects. Many sources show that during their lifespan, as many as 5 percent of persons with a psychotic illness would commit suicide (Hor, 2010). It can be hard to differentiate between schizoaffective disorder and bipolar affective disorder (manicdepressive illness). It is important to note that in clinical practice, schizoaffective disorder is one of the most misdiagnosed psychiatric disorders (Malaspina et al., 2013). In particular, some studies have suggested adjustments to the diagnostic criteria and others have suggested that the condition be excluded from the DSM-5 entirely (Wilson et al., 2014).

Following the analysis of the patient's life history, we can conclude the psychological disorder is present and developing. The late identification of certain behaviors by the family, as well as the other manifestations of the psychological disorders have led to the impairment of the patient's personality and an incapacity to learn proper social behaviors. Schizoaffective disorder, left unchecked, has many consequences on both social functioning and everyday life habits. This would include unemployment, loneliness and impaired self-care capacity.

Negative factors for the prognostic:

- Early Onset - due to the lack of proper social behaviors necessary for social integration, lack of competences such as work experience

- Insidious Onset - the patient had not been treated properly and on time due to family and people close to the patient not being able to identify and interpret certain behaviors as symptoms

Positive factors for the prognostic:

- Good Support System - the patient's sister

- Positive Symptoms (Psychomotor Agitation) - the patient, therefore has a higher rate of remission in regards to treatment

\section{SOURCES OF FUNDING}

This research received no specific grant from any funding agency in the public, commercial, or not-for-profit sectors.

\section{CONFLICT OF INTEREST}

The author have declared that no competing interests exist.

\section{ACKNOWLEDGMENT}

None.

\section{REFERENCES}

[1] American Psychiatric Association. (2013). Diagnostic and statistical manual of mental disorders (DSM-5®). American Psychiatric Pub.

[2] Freud, S. (1923). The Ego and the Id. Internationaler Psycho-analytischer Verlag.

[3] Gunderson, J. (2001). Borderline personality disorder: A clinical guide. American Psychiatric Association.

[4] Hor, K., \& Taylor, M. (2010). Review: Suicide and schizophrenia: a systematic review of rates and risk factors. Journal of Psychopharmacology, 24(4_suppl), 81-90. https://doi.org/10.1177/1359786810385490

[5] Kernberg, O. F. (1993). Severe personality disorders: Psychotherapeutic strategies. Yale University Press. 
[6] Malaspina, D., Owen, M. J., Heckers, S., Tandon, R., Bustillo, J., Schultz, S., Barch, D. M., Gaebel, W., Gur, R. E., Tsuang, M., Van Os, J., \& Carpenter, W. (2013). Schizoaffective disorder in the DSM-5. Schizophrenia Research, 150(1), 21-25. https://doi.org/10.1016/j.schres.2013.04.026

[7] Trifu, S. (2016). Abordare fenomenologică a patologiei psihiatrice majore. Editura Medicală.

[8] Wilson, J. E., Nian, H., \& Heckers, S. (2013). The schizoaffective disorder diagnosis: A conundrum in the clinical setting. European Archives of Psychiatry and Clinical Neuroscience, 264(1), 29-34. https://doi.org/10.1007/s00406-013-0410-7

[9] Wy TJP, Saadabadi A. Schizoaffective Disorder. [Updated 2020 Nov 19]. In: StatPearls [Internet]. Treasure Island (FL): StatPearls Publishing; 2020 Jan-. Available from: https://www.ncbi.nlm.nih.gov/books/NBK541012/ 